\section{Series editors: Susan Lightman and Peter McCluskey}

Correspondence to: Dr Thomas Barrie, Tennent Institute of Ophthalmology, Gartnavel General Hospital, 1053 Great Western Road, Glasgow G12 OYN, UK:

susan.j.campbell@

northglasgow.scot.nhs.uk

Accepted for publication 19 March 2003

\section{Kreissig}

Univ-Augenklinik,

Theodor-Kutzer-Ufer 1-3

68187 Mannheim,

Germany;

ingrid.kreissig@

augen.ma.uni-heidelberg.de

\title{
Repair of a primary rhegmatogenous retinal detachment
}

\author{
T Barrie, I Kreissig, H Heimann, E R Holz, W F Mieler
}

A n emmetropic otherwise well 67 year old man, with no history of eye disease, presents with a rhegmatogenous retinal detachment. The patient needs surgery to repair the detachment. There are three major techniques available to repair the detachmentscleral buckling without drainage, primary vitrectomy, and pneumatic retinopexy. In determining which surgical technique to choose, there are a number of clinical features to consider such as the location and size of the retinal breaks, the presence of media opacities such as cataract, and the presence of proliferative vitreoretinopathy. Additionally, the training and experience of the surgeon is important.

Who should perform the surgery? Which technique should be used? The three invited experts present the case for each technique and discuss their relative advantages and disadvantages.

\section{View 1: Minimal segmental buckling without drainage}

\section{Kreissig}

S cleral buckling involves either an encircling buckle, called cerclage, extending over the entire periphery of the retina with drainage of subretinal fluid or, as refinement, a segmental buckle (elastic sponge) extending over the area of the retinal break(s) and performed without drainage. The latter surgery is called "minimal segmental buckling" (MSB) and represents an extraocular technique for the repair of rhegmatogenous retinal detachments. ${ }^{1}$ The elasticity of the sponge buckle makes it possible to eliminate drainage of subretinal fluid. The buckle and coagulation therapy, either cryopexy or laser, are limited to the area of the break(s). Consequently, it is of utmost importance to identify the break(s) and to position the buckle in the correct location. A further refinement of MSB is the balloon procedure, in which the segmental buckle is a temporary balloon which is not sutured onto the sclera and is withdrawn after a week. A Medline search identified 1462 primary retinal detachments treated with MSB without drainage. The buckle consisted of either segmental sponges ( $\mathrm{n}$ $=962$ detachments $)^{1-6}$ or a temporary balloon (n $=500$ detachments $)^{7}$ with coagulation therapy limited to the area of the break(s).

\section{PROVED ADVANTAGES OF PRIMARY MINIMAL SEGMENTAL BUCKLING WITHOUT DRAINAGE}

The procedure is undertaken under local or topical anaesthesia with inexpensive equipment and few trained additional personnel are required. It can be performed in an outpatient setting and on a low budget. The operating time is rarely more than 45 minutes and is 15-25 minutes with the balloon providing the break(s) are identified before surgery.

After treatment of 1462 detachments with MSB without drainage, the primary attachment rate was $91 \%$. The low rate of further surgery ( $10.7 \%$ had one further procedure and $0.7 \%$ had two) favour MSB. Despite the presence of preoperative proliferative vitreoretinopathy (PVR) grade $\mathrm{C}_{1}-\mathrm{C}_{2}$ in $2.9 \%$, the final attachment rate was $97 \%$ with a 2-15 year follow up. Among causes of final failure are: PVR, $1.9 \%$ and missed breaks, $0.8 \%$ (Table 1 ). There are no intraocular complications (except for a rare choroidal in $0.3 \%$ ) because drainage is eliminated. Secondary glaucoma, cataract, intraocular haemorrhage, intraocular infection, incarceration of retina or vitreous, or iatrogenic tears do not occur because the procedure is extraocular. No postoperative positioning of the patient is required and travelling by aeroplane is not restricted because no gas is injected into the eye. There are no secondary operations in the anterior segment of the eye-for example, phacoemulsification due to a cataract with implantation of an intraocular lens, secondary glaucoma, etc, or in the posterior segmentfor example, removal of silicone oil, etc.

After MSB without drainage, the recovery of visual function is optimal. In a series of 107 detachments (mean preoperative visual acuity 0.3 ) followed for visual acuity, the mean value 
Table 1 Attachment after minimal segmental buckling without drainage of 1462 primary retinal detachments

\begin{tabular}{|c|c|c|c|c|c|c|c|c|}
\hline \multirow[b]{2}{*}{ Series } & \multirow[b]{2}{*}{ Detachments } & \multirow[b]{2}{*}{$\begin{array}{l}\text { Preoperative } \\
\text { PVR }^{*} C_{1}-C_{2}\end{array}$} & \multirow[b]{2}{*}{$\begin{array}{l}\text { Primary } \\
\text { attachment }\end{array}$} & \multirow[b]{2}{*}{$\begin{array}{l}\text { Final } \\
\text { attachment }\end{array}$} & \multicolumn{2}{|c|}{ Cause of final failure } & \multirow[b]{2}{*}{$\begin{array}{l}\text { Mean visual } \\
\text { acuity }\end{array}$} & \multirow[b]{2}{*}{ Follow up } \\
\hline & & & & & PVR $C_{1}-C_{2}$ & $\begin{array}{l}\text { Missed } \\
\text { break }\end{array}$ & & \\
\hline $1 \mathrm{st}^{2,3}$ & 752 & $5(0.7 \%)$ & $672(89 \%)$ & 732 (97\%) & 14 (1.9\%) & $4(0.5 \%)$ & Not available & 2 years \\
\hline $2 n d^{1,4}$ & 107 & $16(15 \%)$ & $99(93 \%)$ & $99(93 \%)$ & $4(3.7 \%)$ & $3(2.8 \%)$ & $0.6 \dagger, 0.5 \ddagger$ & 15 years \\
\hline $3 \mathrm{rd}^{5}$ & 35 & $6(17 \%)$ & $35(100 \%)$ & $35(100 \%)$ & - & - & 0.6 & 2 years \\
\hline $4 \mathrm{th}^{6}$ & 68 & $11(16 \%)$ & 65 (96\%) & $60(88 \%)$ & $8(11.8 \%)$ & - & 0.3 & 2 years \\
\hline $5 \operatorname{th}^{7} \S$ & 500 & $5(1 \%)$ & $454(91 \%)$ & $493(99 \%)$ & $2(0.4 \%)$ & $5(1 \%)$ & 0.7 & $>2$ years \\
\hline Total & 1462 & 43 (2.9\%) & 1325 (91\%) & 1419 (97\%) & $28(1.9 \%)$ & $12(0.8 \%)$ & & 2-15 years \\
\hline \multicolumn{9}{|c|}{$\begin{array}{l}\text { *PVR }=\text { proliferative vitreoretinopathy. } \\
\dagger \text { After } 2 \text { years. } \\
\text { †After } 15 \text { years. } \\
\text { §Treated with temporary balloon buckl }\end{array}$} \\
\hline
\end{tabular}

was 0.6 at 1 year and 0.5 at 15 years. ${ }^{4}$ The observed slight decrease over years is the result of ageing, as confirmed by Slataper after an analysis of 17349 individuals. ${ }^{8}$ Induced changes in refractive error after MSB are minor and do not occur after a temporary balloon buckle.

Therefore, the main advantage of MSB is that it reduces intraoperative and postoperative complications and yields optimal anatomical and functional results over a 2-15 year follow up. All of these factors are of benefit to the elderly patient and the financial resources. This is relevant because the new treatments for macular and retinal diseases are costly.

\section{PRESUMED ADVANTAGES OF PRIMARY MINIMAL SEGMENTAL BUCKLING WITHOUT DRAINAGE}

The minimum of surgical trauma inflicted results in a preservation of the blood-aqueous barrier, because MSB is performed without drainage of subretinal fluid and therefore without decompression of the eye or the injection into the eye to restore intraocular volume. For the surgery itself, no costly disposable instruments or expensive intraocular tamponades are required-for example, heavy perfluorocarbon liquids, expanding gases, or silicone oil-or subsequent surgical removal of the tamponades. Postoperatively, there is a rapid recovery of visual acuity that will not be jeopardised by secondary complications, so no secondary operations are needed.

\section{DISADVANTAGES OF PRIMARY MINIMAL SEGMENTAL BUCKLING WITHOUT DRAINAGE}

Preparation for MSB without drainage, in which the buckle and coagulation are limited to the break, may require extensive preoperative study of the detachment. Detecting breaks preoperatively is less costly, however, as the search uses the time of the surgeon and not the time of additional personnel in attendance in an expensively equipped operating room. Exposure or infection of the sponge buckle can occur, but is less than $0.5 \%$. If a radial sponge is placed in the area of a rectus muscle, diplopia may occur, but can be eliminated with the use of a temporary balloon instead for breaks located beneath a rectus muscle. A prerequisite for MSB without drainage is experience in indirect ophthalmoscopy and microscopy to find all of the breaks and to tamponade them adequately, preferably by a radial buckle. Useful guidelines and indirect wide field contact lenses will help the microscopic search for small breaks in a pseudophakic eye. ${ }^{9-12}$ In the analysed series of 1462 primary retinal detachments, multiple breaks and breaks of various size and constellations were included (excluded were tears $>2$ clock hours in extent and breaks at the posterior pole). With experience in MSB without drainage, reattachment after 1 procedure can be obtained in $91 \%$ and after reoperation in $97 \%$.

The concept of MSB without drainage can be difficult to accept, because the retina does not become attached at the operating table. The surgeon must wait 24 hours or more for the retina to attach spontaneously. However, after spontaneous retinal attachment following MSB without drainage, the rate of redetachment over a 2 year period will be as low as $1.4 \%$ ( retinal detachments) and after a balloon operation without drainage even as low as $0.8 \%$ (series $5=500$ retinal detachments).

\section{CONTROVERSY}

In recent publications, primary vitrectomy has been compared with the results obtained with scleral buckling. However, the authors chose to compare a form of buckling that consisted of a cerclage with additional buckles, extensive coagulation therapy, drainage of subretinal fluid, and often with an intraocular gas or silicone oil tamponade. With that comparison it was concluded that scleral buckling has a higher morbidity than primary vitrectomy. ${ }^{13-15}$ Had they compared primary vitrectomy with MSB without drainage, they would have concluded that segmental buckling has less morbidity than primary vitrectomy. ${ }^{2456716}$ This is the case even though an analysis of 595 detachments treated with vitrectomy, performed by experts, ${ }^{17}$ found that the rate of reoperation is $24.5 \%$ and PVR $11.5 \%$ in contrast with MSB, with a rate of reoperation of $10.7 \%$ and PVR of $1.9 \%$.

\section{REFERENCES}

1 Kreissig I, Rose D, Jost B. Minimized surgery for retinal detachments with segmental buckling and nondrainage. An 1 1-year follow-up. Retina 1992;12:224-31.

2 Lincoff $\mathbf{H}$, Kreissig I, Goldbaum M. Reasons for failure in non-drainage operations. Mod Probl Ophthalmol $1974 ; 12: 40-8$ 


\section{Debate}

3 Lincoff $\mathbf{H}$, Kreissig I. Extraocular repeat surgery of retinal detachment. A minimal approach. Ophthalmology 1996;103:1586-92

4 Kreissig I, Simader E, Fahle M, et al. Visual acuity after segmental buckling and non-drainage: a 15-year follow-up. Eur J Ophthalmol 1995;5:240-6.

5 Sivkova N, Katsarov K, Kreissig I, et al. Our experience in minimized surgery for retinal detachment: first results. folia medica 1997:34: 44-7.

6 Sirtautiene R, Bagdoniene R. Minimised surgery for retinal detachments with segmental buckling and non drainage. In: Xlth Congress of the European Society of Ophthalmology, Budapest 1997. Bologna: Monduzzi Editore SpA 1997:1161-5.

7 Kreissig I, Failer J, Lincoff $\mathrm{H}$, et al. Results of a temporary balloon buckle in the treatment of 500 retinal detachments and a comparison with pneumatic retinopexy. Am J Ophthalmol 1989;107:381-9.

8 Slataper FJ. Age norms of refraction and vision. Arch Ophthalmol 1950;43:466-79.

9 Lincoff H, Gieser R. Finding the retinal hole. Arch Ophthalmol 1971:85:565-569.

10 Lincoff $\mathbf{H}$, Kreissig I. Finding the retinal hole in the pseudophakic eye with detachment. Am J Ophthalmol 1994; 117:442-6.
11 Kreissig I. A practical guide to minimal surgery for retinal detachment. Vol 1. Stuttgart, New York: Thieme, 2000; back cover of book.

12 Kreissig I. A practical guide to minimal surgery for retinal detachment. Vol 2. Stuttgart, New York: Thieme, 2000 , back cover of book.

13 Framme C, Roider J, Hoerauf $\mathrm{H}$, et al. Complications after external retinal surgery in pseudophakic retinal detachment-are scleral buckling operations still current? Klin Monatsbl Augenheilkd 2000;216:25-32.

14 Tornambe PE, Hilton GF, Brinton DA, et al. Pneumatic retinopexy. A two-year follow-up study of the multicenter clinical trial comparing pneumatic retinopexy with scleral buckling. Ophthalmology 1991;98:1115-23.

15 Bartz-Schmidt KU, Kirchhof B, Heimann K. Primary vitrectomy for pseudophakic retinal detachment. $\mathrm{Br} J$ Ophthalmol 1996;80:346-9.

16 Lincoff $\mathbf{H}$, Kreissig I. Changing patterns in the surgery for retinal detachment: 1929 to 2000 . Klin Monatsb Augenheilkd 2000; 21 6:352-9.

17 Kreissig I. A practical guide to minimal surgery for retinal detachment. Vol 2. Stuttgart, New York: Thieme 2000;13:305, Table 13.2.

\section{View 2: The case for primary vitrectomy}

\section{The SPR Study group*}

${ }^{*}$ A complete list of participants is provided in the SPR Study report No 1')

H Heimann Eye Department, University Hospital Benjamin Franklin, Free University Berlin Hindenburgdamm 30 12200 Berlin, Germany; heinrich.heimann@ medizin.fu-berlin.de
$T$ he term "primary vitrectomy for rhegmatogenous retinal detachment" implies that pars plana vitrectomy is the first surgical intervention in the treatment of this disease. In the literature, however, its definition is frequently widened: it often includes patients with rhegmatogenous retinal detachment (RRD) who have undergone either cryotherapy or photocoagulation for retinal breaks or small detachments before vitrectomy, although, strictly speaking, pars plana primary vitrectomy (PPPV) is not the first surgical intervention in these cases. The following assessment is based on the analysis of 25 publications of primary vitrectomy listed in Table 1 .

\section{ADVANTAGES OF PRIMARY VITRECTOMY}

The removal of opacities in the vitreous and of capsular remnants or synechia are clear advantages of PPPV. The better intraoperative control of PPPV is supported by the high rates of intraoperative

Table 1 Reports of primary vitrectomy for the treatment of rhegmatogenous retinal detachment

\begin{tabular}{|c|c|c|c|c|c|c|c|c|c|}
\hline \multirow[b]{2}{*}{ Author } & \multirow[b]{2}{*}{ Year } & \multirow[b]{2}{*}{ Buckle } & \multirow[b]{2}{*}{ No } & \multirow[b]{2}{*}{$\begin{array}{l}\text { Primary } \\
\text { success }\end{array}$} & \multirow[b]{2}{*}{$\begin{array}{l}\text { Final } \\
\text { success }\end{array}$} & \multirow[b]{2}{*}{ PVR } & \multicolumn{3}{|l|}{ VA } \\
\hline & & & & & & & $\geqslant 0.33$ & $\geqslant 0.4$ & $\geqslant 0.5$ \\
\hline Escoffery $^{17}$ & 1985 & $0 \%$ & 29 & $79 \%$ & $79 \%$ & $7 \%$ & & $76 \%$ & \\
\hline van Effenterre ${ }^{18}$ & 1987 & $0 \%$ & 60 & $86 \%$ & $92 \%$ & $0 \%$ & & $76 \%$ & \\
\hline Hakin $^{19}$ & 1993 & $79 \%$ & 124 & $64 \%$ & $82 \%$ & & $34 \%$ & & \\
\hline Gartry $^{13}$ & 1993 & $65 \%$ & 114 & $74 \%$ & $92 \%$ & $8 \%$ & $35 \%$ & & \\
\hline Girard $^{20}$ & 1995 & $81 \%$ & 103 & $74 \%$ & $85 \%$ & $16 \%$ & & & $40 \%$ \\
\hline Höing $^{21}$ & 1995 & $0 \%$ & 32 & $78 \%$ & $94 \%$ & $19 \%$ & & & $44 \%$ \\
\hline Bartz-Schmidt ${ }^{5}$ & 1996 & $100 \%$ & 33 & $94 \%$ & $100 \%$ & $3 \%$ & & $79 \%$ & \\
\hline Heimann ${ }^{22}$ & 1996 & $0 \%$ & 53 & $64 \%$ & $92 \%$ & $6 \%$ & & $41 \%$ & \\
\hline Yang $^{23}$ & 1997 & $100 \%$ & 9 & $89 \%$ & $100 \%$ & $0 \%$ & & $0 \%$ & \\
\hline El-Asrar ${ }^{10}$ & 1997 & $100 \%$ & 22 & $100 \%$ & $100 \%$ & $0 \%$ & & $32 \%$ & \\
\hline Desai ${ }^{24}$ & 1997 & $100 \%$ & 10 & $100 \%$ & $100 \%$ & $0 \%$ & & $70 \%$ & \\
\hline Hoerauf 25 & 1997 & $83 \%$ & 37 & $87 \%$ & & $8 \%$ & & & \\
\hline Sharma $^{7}$ & 1998 & $100 \%$ & 21 & $90 \%$ & $90 \%$ & $10 \%$ & & $19 \%$ & \\
\hline Brazitikos $^{26}$ & 1999 & $36 \%$ & 14 & $100 \%$ & $100 \%$ & $0 \%$ & & $69 \%$ & \\
\hline $\mathrm{Campo}^{27}$ & 1999 & $0 \%$ & 275 & $88 \%$ & $96 \%$ & $6 \%$ & & $69 \%$ & \\
\hline Devenyi $^{6}$ & 1999 & $100 \%$ & 94 & $100 \%$ & $100 \%$ & $0 \%$ & & & \\
\hline Newman ${ }^{28}$ & 1999 & $48 \%$ & 25 & $84 \%$ & $96 \%$ & $8 \%$ & & & $48 \%$ \\
\hline Oshima $^{29}$ & 1999 & $51 \%$ & 63 & $92 \%$ & $100 \%$ & $0 \%$ & & & \\
\hline Brazitikos $^{30}$ & 2000 & & 103 & $93 \%$ & $97 \%$ & $4 \%$ & & & \\
\hline Brazitikos $^{30}$ & 2000 & $0 \%$ & 20 & $85 \%$ & $95 \%$ & $10 \%$ & & & \\
\hline Gastaud $^{31}$ & 2000 & $58 \%$ & 19 & $84 \%$ & $100 \%$ & $0 \%$ & & & \\
\hline Pournaras $^{32}$ & 2000 & $100 \%$ & 23 & $92 \%$ & $100 \%$ & $4 \%$ & & $65 \%$ & \\
\hline Speicher $^{33}$ & 2000 & $0 \%$ & 78 & $94 \%$ & $96 \%$ & $5 \%$ & & & \\
\hline$M_{i k i}{ }^{8}$ & 2000 & & 87 & $92 \%$ & $100 \%$ & $1 \%$ & & & \\
\hline Tanner $^{34}$ & 2001 & $0 \%$ & 9 & $89 \%$ & $100 \%$ & $0 \%$ & & $67 \%$ & \\
\hline
\end{tabular}


reattachment, even in very difficult cases, achieved by internal drainage and endotamponade. This is further emphasised by the low rate of intraoperative complications, the most frequently observed being iatrogenic breaks (6\% of cases in series reporting this complication), and that of lens damage in phakic eyes in 3\%. Surgeons nowadays have become more familiar with this technique compared to scleral buckling surgery, as the indications for vitrectomy and the total number of cases outside retinal detachment surgery have increased immensely during the past decade. Further, endoillumination, indentation, a higher magnification, wide angle viewing systems, the removal of opacities, membranes, and the unfolding of detached retina with perfluorocarbon liquids enable a better view of the pathological anatomy and an improvement in the identification of previously unseen breaks, as documented in 77 of 87 cases of previously unseen breaks. The problems associated with external drainage, such as choroidal haemorrhage, retinal incarceration, and retinal perforation, as well as that of scleral perforation during suturing of the exoplant (if PPPV is not combined with additional scleral buckling surgery) are avoided.

In the postoperative period, major drawbacks of scleral buckling surgery are avoided: only minor changes of refraction occur compared to those following scleral buckling surgery. Choroidal detachments, summarised by Ambati and Arroyo to occur in $23-44 \%$ of eyes following scleral buckling surgery, ${ }^{2}$ have been reported in only three patients following PPPV. Infections, intrusions, and extrusions of episcleral buckling material complicating scleral buckling surgery are precluded completely (if no additional scleral buckling is performed) and have not been reported in the literature reviewed above. Postoperative imbalance of extraocular muscles, leading to long term diplopia occurring in 5-25\% following scleral buckling surgery, ${ }^{3}$ have not been mentioned in the series summarised in Table 1.

\section{PRESUMED ADVANTAGES OF PPPV}

One of the major reasons for the increasing use of PPPV is the expectation that better anatomical and functional results are achieved with this method in more complicated forms of RRD. The combined primary success rate of the studies of PPPV reviewed was $85 \%$. Compared to the primary success rates of larger, consecutive studies of scleral buckling surgery (75-91\%) summarised by Wilkinson, ${ }^{4}$ this further encourages the use of PPPV, particularly as more complex situations of RRD are operated on with PPPV. PPPV is thought to be particularly successful in pseudophakic/ aphakic patients, as demonstrated by the high primary success rates of $91 \%$ that seems to be significantly superior to those of scleral buckling. ${ }^{4}$ In these situations, a more thorough removal of the peripheral vitreous is possible. Further, unclear hole situations and small retinal breaks are more common; and postoperative cataract formation is not a concern. Moreover, the overall final success rates of $95 \%$ with PPPV in more complex cases of RRD seem to be exceptionally good compared to the majority of reports of scleral buckling surgery (range $88-97 \%$ ), and in $98 \%$ of pseudophakic and aphakic patients compared to $80-96 \% .{ }^{4}$ One of the presumed advantages of PPPV might be that redetachments following PPPV are "easier" cases compared to failures after scleral buckling surgery. The former are often caused by a single missed/new break, and a repetition of the internal tamponade with treatment of the new break is frequently sufficient to treat the redetachment. However, for methodological reasons (for example, differences of inclusion criteria, operating techniques, follow up period, or measurement of visual acuity in various series of scleral buckling surgery and PPPV), the data provided to date are inadequate for a sound comparison of anatomical or functional results of PPPV and scleral buckling surgery. The same holds true for postoperative proliferative vitreoretinopathy (PVR) formation and macular pucker. Although various hypotheses about why PPPV should result in a lowering of postoperative PVR have been proposed (for example, removal of the vitreous with its chemotactic and mitogenic stimuli, and the "washout" of RPE cells out of the subretinal space and vitreous cavity ${ }^{6}$ ), there still are considerable rates of postoperative PVR in 6\% of all patients following PPPV. Furthermore, macular pucker was seen in $9 \%$ of patients in studies in which this complication was investigated. Finally, the supremacy of functional results following PPPV has yet to be proved, although the calculated percentage of $63 \%$ of patients with a visual acuity of 0.4 or better in series of PPPV summarised in Table 1 compares very favourably with the $39-56 \%$ of successful cases only following scleral buckling surgery. ${ }^{4}$ Again, the functional results following PPPV in pseudophakic/aphakic patients seem to be even more superior to scleral buckling surgery when comparing the published results. However, the need for appropriate data is underlined by two recent retrospective studies which compared PPPV to scleral buckling in more complex situations of RRD and another series including patients with flap tears only. ${ }^{89}$ Neither study could demonstrate a significant advantage of PPPV over scleral buckling concerning anatomical and functional success.

\section{DISADVANTAGES OF PPPV}

The major intraoperative complication, iatrogenic breaks (although supposedly not significantly influencing the outcome of the surgery), will probably not be completely eliminated even if the greatest intraoperative care is taken. The same holds true for intraoperative damage to the lens and the postoperative increase in nuclear cataract, which was established in more than a third of phakic patients. These complications not only cause a decrease in visual acuity and a myopic shift of postoperative refraction but will cause loss of accommodation in young patients and, sooner or later, lead to the necessity of additional surgery in most patients. If similar success rates can be achieved with both surgical methods, this has to be seen not only from the patient's point of view but also against the background of the management of surgical and financial resources. The same reasoning has to be applied regarding the costs of the procedure of PPPV itself. These are significantly higher compared to scleral buckling surgery alone, although some authors argue that PPPV is cheaper than scleral buckling surgery in 


\section{Debate}

the long run, because of a higher anatomical success rate and lower number of reoperations following PPPV. ${ }^{6}$

Analysis of the literature would further suggest that a greater number of postoperative breaks can be found following PPPV compared to scleral buckling surgery. No definite distinction can be made if a break, which is detected postoperatively, has developed de novo or has just been missed before or during the surgery. However, if one postulates that more breaks are identified during PPPV compared to scleral buckling surgery, there is no other explanation for the high rate of postoperative breaks compared to series of conventional surgery than that these breaks developed after the initial surgery. Possible mechanisms for the development of new breaks following PPPV are accidental touching of the retina during surgery that will later result in a retinal tear; new tangential forces from scar formation, especially in the region of the sclerotomies; contraction forces of the remaining vitreous cortex; formation and contraction of an epiretinal membrane; and/or continuing PVD after PPPV. ${ }^{8}{ }^{10} 11$ Finally, it is worth mentioning that four series of PPPV have identified a total of 27 patients with a long lasting rise in the intraocular pressure following the procedure.

\section{CONTROVERSIES ABOUT THE CURRENT USE OF PRIMARY VITRECTOMY}

PPPV has gained a tremendous popularity in recent years and in some centres in the United Kingdom, PPPV is the method of choice in up to $63 \%$ of all patients with RRD. ${ }^{12}$ The major advantage of PPPV that has been established to date and the main reason for its current popularity is that it lowers the intraoperative complication rate and enables better control in more challenging situations of RRD. ${ }^{13}$ By changing the operative method to PPPV in such situations, the surgeon avoids the hazards of scleral perforation and external drainage; bad visualisation of the retinal periphery; a very soft eyeball during surgery; "fish-mouthing" in awkward breaks; insufficient elimination of vitreous traction on the break; or very difficult placement of scleral buckles in complicated break arrangements. During surgery, it is possible to work in a pressure stable environment, to clear media opacities, have an enhanced view to look and search for peripheral breaks, and to reattach the retina in almost every case, no matter how complicated the preoperative anatomical situation might have been. In "unclear hole situations," it is unnecessary to search for breaks for several hours or days, as proposed, because it is highly likely that these breaks will be detected during the operation. The patient will leave the operating table with a reattached retina supported by an internal tamponade and with the belief that all breaks have been identified and treated. This leads to more confidence for the surgeon compared to the worries one might have because of either patent breaks with residual detachment, which should hopefully be absorbed during the following the early postoperative days; "blind" circular encirclements which, with a bit of luck, may or may not work; or extensive external cryotherapy. These advantages of PPPV are increasingly often willingly "traded in" for additional cataract surgery in phakic patients, which nowadays does not present a major surgical problem for the vitrectomised eye, and is even more easily accepted in pseudophakic eyes.

Scleral buckling surgery might be a straightforward, highly successful procedure in simple cases with good visualisation of the retinal situation, and it is doubtful that PPPV will gain much popularity in this field, even in pseudophakic cases. However, in more complicated situations of RRD, the surgical procedure of scleral buckling surgery very quickly becomes much more challenging and the expressions of the "art" of scleral buckling surgery and the "surgical nerve" required are sometimes used. ${ }^{14}$ If PPPV simplifies the treatment of more complicated retinal detachments and enables surgeons to manage more complex situations of RRD at an earlier stage, the question is whether it would be justified to expose training surgeons and patients to the longer learning curve of mastering scleral buckling in complicated situations of RRD.

In addition, the very high success rates reported for non-drainage procedures ${ }^{15}$ are not comparable to other reports of RRD surgery, as a different selection of patients and dissimilar definition of primary success and redetachment is used in reports of non-drainage surgery. With the "minimal surgery" approach or conventional scleral buckling surgery, even most recent series ${ }^{16}$ fail to reproduce the high success rates of selected reports of non-drainage scleral buckling surgery. ${ }^{14}{ }^{15}$ Regarding the cost of the surgery, market forces and the policy of cutting down on expenses in the medical sector will result in favouring the cheaper one of two methods if similar results are achieved. Further, despite the increasing numbers of vitrectomies for other indications, RRD will remain one of the major indications for vitreoretinal surgery, as no measures can be undertaken to prevent the disease as yet and the absolute numbers of patients with RRD is rising owing to the increasing age of the population and number of cataract surgeries performed.

The techniques of scleral buckling surgery have been established for decades and no further enhancements have been introduced in recent years. This is reflected by the fact that the results published in recent series of scleral buckling surgery $^{16}$ are not superior to the results achieved 20 years earlier. ${ }^{4}$ In contrast, the techniques of PPPV are constantly refined and with the prospects of a medical vitreolysis, and the uncomplicated installation of as yet hypothetical drugs that might lower postoperative PVR, additional advantages of PPPV are to be expected in the future. As indicated by numerous authors previously, however, only a prospective, multicentre randomised trial will be able to provide sufficient data to define the exact role of PPPV in the treatment of RRD. Such a trial, the "Scleral Buckling versus Primary Vitrectomy in Rhegmatogenous Retinal Detachment Study (SPR Study)," is currently under way in 25 centres in Europe. ${ }^{1}$

\section{REFERENCES}

1 Heimann $\mathbf{H}$, Hellmich $M$, Bornfeld $N$, et al. Scleral buckling versus primary vitrectomy in rhegmatogenous retinal detachment (SPR Study): design issues and implications. SPR Study report no 1. Graefes Arch Clin Exp Ophthalmol 2001;239:567-74. 
2 Ambati J, Arroyo JG. Postoperative complications of scleral buckling surgery. Int Ophthalmol Clin 2000;40:175-85.

3 Farr AK, Guyton DL. Strabismus after retinal detachment surgery. Curr Opin Ophthalmol 2000;1 1:207-10.

4 Wilkinson CP, Rice TA. Results of retinal reattachment surgery. In: Michel's retinal detachment. 2 nd ed. St Louis: Mosby, 1997:935-78.

5 Bartz-Schmidt KU, Kirchhof B, Heimann K. Primary vitrectomy for pseudophakic retinal detachment. $\mathrm{Br} J$ Ophthalmol 1996;80:346-9.

6 Devenyi RG, de Carvalho Nakamura H. Combined scleral buckle and pars plana vitrectomy as a primary procedure for pseudophakic retinal detachments. Ophthalmic Surg Lasers 1999;30:615-8.

7 Sharma T, Gopal L, Badrinath SS. Primary vitrectomy for rhegmatogenous retinal detachment associated with choroidal detachment. Ophthalmology 1998:105:2282-5

8 Miki D, Hida T, Hotta K, et al. Comparison of scleral buckling and vitrectomy for retinal detachment resulting from flap tears in superior quadrants. Jpn J Ophthalmol 2000;45: 187-91.

9 Oshima Y, Yamanishi S, Sawa M, et al. Two-year follow-up study comparing primary vitrectomy with scleral buckling for macula-off rhegmatogenous retinal detachment. Jpn J Ophthalmol 2000;44:538-49.

10 El-Asrar AM. Primary vitrectomy for bullous rhegmatogenous retinal detachments due to complex breaks. Eur J Ophthalmol 1997;7:322-6.

11 Okada K, Sakata H, Mizote H, et al. Postoperative posterior retinal holes after pars plana vitrectomy for primary retinal detachment. Retina 1997;17:99-104.

12 Minihan M, Tanner V, Williamson TH. Primary rhegmatogenous retinal detachment: 20 years of change. Br J Ophthalmol 2001;85:546-8.

13 Gartry DS, Chignell AH, Franks WA, et al. Pars plana vitrectomy for the treatment of rhegmatogenous retinal detachment uncomplicated by advanced proliferative vitreoretinopathy [see comments]. Br J Ophthalmol 1993;77:199-203.

14 Lincoff $\mathbf{H}$, Kreissig I. Changing patterns in the surgery for retinal detachment: 1929 to 2000 . Klin Monatsbl Augenheilkd 2000;216:352-9.

15 Kreissig I, Simader E, Fahle $M$, et al. Visual acuity after segmental buckling and non-drainage: a 15-year follow-up. Eur J Ophthalmol 1995;5:240-6.

16 Framme C, Roider J, Hoerauf $\mathrm{H}$, et al. [Complications after external retinal surgery in pseudophakic retinal detachment-are scleral buckling operations still current?] Klin Monatsbl Augenheilkd 2000;216:25-32.

17 Escoffery RF, Olk RJ, Grand MG, et al. Vitrectomy without scleral buckling for primary rhegmatogenous retinal detachment. Am J Ophthalmol 1985;99:275-81.

18 Van Effenterre G, Haut J, Larricart P, et al. Gas tamponade as a single technique in the treatment of retinal detachment: is vitrectomy needed? A comparative study of 120 cases. Graefes Arch Clin Exp Ophthalmol 1987;225:254-8.
19 Hakin KN, Lavin M, Leaver PK. Primary vitrectomy for rhegmatogenous retinal detachment. Graefes Arch Clin Exp Ophthalmol 1993;231:344-6.

20 Girard P, Karpouzas I. [Vitrectomy in the treatment of simple retinal detachment.] J Fr Ophtalmol 1995; 18:188-93.

21 Hoing C, Heidenkummer HP, Kampik A. [Primary vitrectomy in rhegmatogenous retinal detachment.] Ophthalmologe 1995;92:668-71.

22 Heimann $\mathbf{H}$, Bornfeld $N$, Friedrichs $W$, et al. Primary vitrectomy without scleral buckling for rhegmatogenous retinal detachment. Graefes Arch Clin Exp Ophthalmol 1996;234:561-8.

23 Yang CM. Pars plana vitrectomy in the treatment of combined rhegmatogenous retinal detachment and choroidal detachment in aphakic or pseudophakic patients. Ophthalmic Surg Lasers 1997:28:288-93.

24 Desai UR, Strassman IB. Combined pars plana vitrectomy and scleral buckling for pseudophakic and aphakic retinal detachments in which a break is not seen preoperatively. Ophthalmic Surg Lasers 1997;28:718-22.

25 Hoerauf H, Roider J, Herboth T, et al. [Outcome after vitrectomy in rhegmatogenous retinal detachment and dense vitreous opacities.] Klin Monatsbl Augenheilkd 1997;211:369-74.

26 Brazitikos PD, D'Amico DJ, Tsinopoulos IT, et al. Primary vitrectomy with perfluoro-n-octane use in the treatment of pseudophakic retinal detachment with undetected retinal breaks. Retina 1999;19:103-9.

27 Campo RV, Sipperley JO, Sneed SR, et al. Pars plana vitrectomy without scleral buckle for pseudophakic retinal detachments. Ophthalmology 1999;106:1811-15; discussion 1816

28 Newman DK, Burton RL. Primary vitrectomy for pseudophakic and aphakic retinal detachments. Eye 1999; 13:635-9.

29 Oshima Y, Emi K, Motokura M, et al. Survey of surgical indications and results of primary pars plana vitrectomy for rhegmatogenous retinal detachments. Jpn J Ophthalmol 1999;43:120-6.

30 Brazitikos PD. The expanding role of primary pars plana vitrectomy in the treatment of rhegmatogenous noncomplicated retinal detachment. Sem Ophthalmol 2000; 15:65-77

31 Gastaud P, Rouhette $\mathrm{H}$, Negre F, et al. [Place of "exploratory vitrectomy" in the treatment of retina detachment without proliferative vitreoretinopathy.] J Fr Ophtalmol 2000;23:482-7.

32 Pournaras CJ, Donati G, Sekkat L, et al. [Pseudophakic retinal detachment:treatment by vitrectomy and scleral buckling. Pilot study.] J Fr Ophtalmol 2000;23:1006-1 1

33 Speicher MA, Fu AD, Martin JP, et al. Primary vitrectomy alone for repair of retinal detachments following cataract surgery. Retina 2000;20:459-64.

34 Tanner V, Minihan M, Williamson TH. Management of inferior retinal breaks during pars plana vitrectomy for retinal detachment. Br J Ophthalmol 2001;85:480-2.

\title{
View 3: The case for pneumatic retinopexy
}

\author{
E R Holz, W F Mieler
}

$\mathrm{P}$ neumatic retinopexy (PR) is a minimally invasive technique for the repair of rhegmatogenous retinal detachment (RRD). It is composed of intravitreal gas injection, either cryopexy or laser, and postoperative positioning.

\section{ADVANTAGES OF PR}

Given an optimal clinical scenario, PR has several advantages over primary pars plana vitrectomy (PPV) and/or scleral buckle (SB) for the repair of an RRD. Pneumatic retinopexy is usually performed in the office or as a brief procedure in an outpatient surgical facility. In a multicentre trial

reported by Tornambe, ${ }^{1}$ the average number of hospital days including reoperations was 0.6 for the PR group and 2.7 for the SB group. The physician spends less time waiting for availability of the operating room, performing the procedure, and performing postoperative hospital rounds. It should be noted, however, that since this publication in 1989, the majority of procedures, including PR, primary PPV, and SB, are now performed in an outpatient setting.

With PR, the patient generally experiences less pain, and there is a quicker recovery in the more comfortable home setting. There is also a significant economic advantage to the patient and the

\section{Debate}


insurer in terms of cost savings by avoiding the operating room, anaesthesia, and hospital expenses. It is estimated that the cost of PR is between $25 \%$ and $50 \%$ that of SB including re-operations. ${ }^{2}$

Pneumatic retinopexy is a technically easy procedure. There are very few significant intraoperative complications. When they do occur, it generally involves improper location of the injected air or gas, generally into the subconjunctival or subretinal space-in only $0-10 \%$ and $0-4 \%$ of cases. ${ }^{1-7} \mathrm{New}$ and/or missed retinal breaks are created in $7-33 \%$ of cases. ${ }^{1-10}$

There are more significant risks associated with primary PPV and SB procedures. Primary PPV surgery has a much higher incidence of lens injury/cataract $(3 \%)$ and other anterior segment complications such as intraocular lens (IOL) subluxation, iris capture, and flat anterior chamber. ${ }^{11}{ }^{12}$ Scleral buckle procedures are associated with significant risks primarily due to inadvertent scleral perforation $(5 \%)$ or during drainage of subretinal fluid. ${ }^{313-15}$ Subretinal haemorrhage $(3.0-4.5 \%)$, retinal incarceration $(2.2-3.0 \%)$, retinal breaks $(0.54-4.0 \%)$, and vitreous loss $(0.36-3.0 \%)$ are all significant risks associated with drainage sites. ${ }^{33-15}$ Postoperative diplopia is ubiquitous with SB procedures, being reported in up to $20-50 \%$ of cases. ${ }^{16}{ }^{17}$

Postoperative complications of PR are rare with the exception of new and/or missed retinal breaks. Epiretinal membrane (ERM), cystoid macular oedema (CMO), macular hole ( $\mathrm{MH})$, and proliferative vitreoretinopathy (PVR) rates are all less than or equal to published risk rates for $\mathrm{SB}$ and PPV (Table 1). ${ }^{1-10} 1617$

Functional visual results of the three techniques are an area of significant controversy. It is well recognised that PR and primary PPV both avoid the significant induced myopia associated with SBs. The induced changes in refractive error can, in some cases, produce significant anisometropia requiring contact lens use or even refractive surgery. A large multicentre trial comparing SB and PR found a significant visual benefit with PR. For eyes with preoperative macular detachment of less than 2 weeks' duration, the percentage of patients achieving $20 / 50$ or better best corrected visual acuity was $80 \%$ for PR and $56 \%$ for SB. ${ }^{1}$ Two retrospective, comparative series by Han ${ }^{9}$ and McAllister, ${ }^{18}$ however, found no statistically significant difference in visual outcomes between the two procedures. Similar data for primary PPV are unavailable for a meaningful comparison; however, the positive impact of the clearance of vitreous floaters and debris cannot be underestimated.

\section{DISADVANTAGES OF PR}

Anatomical success is the key issue regarding surgical techniques for the repair of RRD. The cumulative initial success rate for the surveyed papers was $75.5 \%$, with a final overall success of $97.4 \%$. This is lower than reported rates for PPV $(85 \%)$ and SB ( 1440 of 1630 cases, $88 \%) .{ }^{19-21}$ The case selection for PR typically involves simple anatomy so matching for similar cases done with PR or SB might uncover a larger disparity in success rates. A prospective, randomised, multicentre trial comparing $\mathrm{PR}$ with $\mathrm{SB}$ found a lower primary success rate with PR (73\%) versus SB (82\%), but a similar final success rate of $99 \%$ versus $98 \%$ respectively. ${ }^{1}$ A retrospective comparative series by McAllister ${ }^{18}$ found a higher success rate for SB (96\%) compared to PR (71\%). However, when aphakic and pseudophakic eyes with open posterior capsule were excluded, the success rate for PR improved to $81 \% .^{18}$ A similar study by $\mathrm{Han}^{9}$ found a higher anatomical success rate for SB (84\% versus $62 \%$ ) but an equal final success rate of $98 \%$. The data support the fact that for $\mathrm{RRD}, \mathrm{SB}$, and primary PPV offer superior initial success rates, yet equivalent final anatomical success rates.

Pneumatic retinopexy has a lower initial success rate for two major reasons: (1) reopening of the original break; and (2) new and/or missed retinal breaks. Both SB and primary PPV permanently relieve vitreoretinal traction and therefore, retinal tear reopening is a relatively rare phenomenon. With PR, there is no relief of traction so that the laser or cryopexy induced chorioretinal adhesion must be strong enough to overcome this tractional force on the retina. New and/or missed retinal breaks are more commonly encountered with PR than with PPV or SB. One contributing factor for missed breaks may be the extent of retinal examination performed with each technique. All patients undergo extensive retinal examination before any of the three surgical procedures, but SB and primary PPV provide additional examination opportunities. During SB, an examination under anaesthesia with open conjunctival scleral depression is routinely performed, thereby allowing the discovery of previously missed breaks. Pars plana vitrectomy, especially when performed under wide field viewing, allows extensive, high magnification, peripheral examination under anaesthesia. In addition, PPV will remove media opacities such as an opacified posterior capsule, vitreous haemorrhage, or vitreous debris resulting in a superior view of the retinal periphery.

New retinal breaks do occur following PR. It is postulated that a gas bubble within the vitreous

Table 1 Comparison of postoperative complications

\begin{tabular}{llll}
\hline & $\begin{array}{l}\text { Pneumatic } \\
\text { retinopexy }\end{array}$ & $\begin{array}{l}\text { Pars plana } \\
\text { vitrectomy }\end{array}$ & Scleral buckle \\
\hline Epiretinal membrane & $2-11 \%$ & $0-18 \%$ & $4-17 \%$ \\
Cystoid macular oedema & $0-8 \%$ & $0-17 \%$ & $30-43 \%$ \\
Macular hole & $0-3 \%$ & $0-2 \%$ & - \\
Proliferative vitreoretinopathy & $3-13 \%$ & - & $5-10 \%$ \\
Cataract & $1-20 \%$ & $38 \%$ & $0-50 \%$ \\
Diplopia & - & - & $20-50 \%$ \\
\hline
\end{tabular}


cavity creates additional vitreoretinal traction, particularly when the bubble is positioned between the retina and posterior hyaloid face. These breaks may occur in any quadrant, but $76 \%$ are located in the superior two thirds of the retina and $52 \%$ are located within 3 clock hours of the original causative break. The majority (59\%) of new breaks occur during the first postoperative month. ${ }^{1}$ Prophylactic $360^{\circ}$ peripheral barricade laser has been advocated to reduce the risk of new and/or missed retinal breaks. Tornambe ${ }^{2}$ found a single operation success rate of 55\% when focal retinopexy was employed compared to $85 \%$ for patients following $360^{\circ}$ retinopexy. Presumably this difference was because of a lower number of failures as a result of new and/or missed breaks in the $360^{\circ}$ retinopexy group.

\section{CONTROVERSIES ABOUT THE CURRENT USE OF PNEUMATIC RETINOPEXY}

Significant controversy surrounds the current use of PR for repair of RRD. Most of this controversy revolves around the issue of case selection. Certainly the ideal clinical scenario for PR is that of a phakic detachment because of a single break or small group of breaks in the superior two thirds of the fundus without additional retinal pathology. Tornambe reported a $97 \%$ single operation success rate in this subgroup of patients. ${ }^{2}$ Scleral buckle and primary PPV probably have similar success rates in this situation; however, the risk profile, patient morbidity, and cost involved favour the use of PR. The success rate for pseudophakic and aphakic detachments is lower presumably as a result of the increased number of small breaks in multiple quadrants and potentially an impaired view of the peripheral retina in pseudophakic eyes. Nevertheless, PR can still be employed successfully in these cases when all the breaks are identified and located preoperatively in a single quadrant. Occasionally, by using a second gas injection or repositioning the patient, detachments with breaks in more than one quadrant can be by addressed by PR. ${ }^{22}$

The size of the causative retinal break has been another area of concern. Air or gas may be more prone to migrate into the subretinal space through large breaks, and the arc of contact of the bubble may not be broad enough to tamponade the entire break. Reports exist of the successful use of PR for RRDs caused by giant retinal tear (four of five cases, $80 \%$ ), retinal dialysis (four of four cases, $100 \%$ ), and other large breaks. ${ }^{23-25}$ These case series demonstrate that PR can be effective even in cases with large breaks, particularly if they are located superiorly and lack significant vitreoretinal traction. Pneumatic retinopexy has generally been avoided for RRD caused by breaks in the inferior 4 clock hours. Acute, phakic, inferior detachments with single breaks have been managed successfully in two instances by the author (ERH) using a head dangling position. It is evident that although PR has an "ideal" scenario for its chief indication, the technique is more widely applicable in certain select cases for those with multiple breaks, large breaks, and even breaks located in the inferior four clock hours.

\section{REFERENCES}

1 Tornambe PE, Hilton GF, The Retinal Detachment Study Group. Pneumatic retinopexy: a multicenter randomized controlled clinical trial comparing pneumatic retinopexy with scleral buckling. Ophthalmology 1989;96:772-84.

2 Tornambe PE. Pneumatic retinopexy: the evolution of case selection and surgical technique. A twelve-year study of 302 eyes. Trans Am Ophthalmol Soc 1997;95:551-78.

3 Hilton GF, Grizzard WS. Pneumatic retinopexy: a two-step outpatient operation without conjunctival incision. Ophthalmology 1986;93:626-41.

4 Hilton GF, Kelly NE, Salzano TC, et al. Pneumatic retinopexy: a collaborative report of the first 100 cases. Ophthalmology 1987;94:307-14.

5 Assi AC, Charteris DG, Pearson RV, et al. Pneumatic retinopexy in the treatment of primary rhegmatogenous retinal detachment. Eye 1999;13:725-8.

6 Lowe MA, McDonald R, Campo RV, et al. Pneumatic retinopexy: surgical results. Arch Ophthalmol 1988;106:1672-6

7 Abecia E, Pinilla I, Olivan JM, et al. Anatomic results and complications in a long-term follow-up of pneumatic retinopexy cases. Retina 2000;20:156-61.

8 Chen JC, Robertson JE, Coonan P, et al. Results and complications of pneumatic retinopexy. Ophthalmology 1988;95:601-8

9 Han DP, Mohsin NC, Guse CE, The Southeastern Wisconsin Pneumatic Retinopexy Study Group. Comparison of pneumatic retinopexy and scleral buckling in the management of primary rhegmatogenous retinal detachment. Am J Ophthalmol 1998;1 26:658-68.

10 Lisle C, Mortensen KK, Sjolie AK. Pneumatic retinopexy: a long term follow-up study. Acta Ophthalmol Scand 1998;76:486-90.

11 Campo RV, Sipperley JO, Sneed SR, et al. Pars plana vitrectomy without scleral buckle for pseudophakic retinal detachments. Ophthalmology 1999;106:1811-16.

12 Speicher MA, Fu AD, Martin JP, et al. Primary vitrectomy alone for repair of retinal detachments following cataract surgery. Retina 2000;20:459-64.

13 Wilkinson CP, Bradford RH Jr. Complications of draining subretinal fluid. Retina 1984;4:1-4.

14 Hilton GF, McLean EB, Norton EWD. Retinal detachment. San Francisco: American Academy of Ophthalmology, 1979.

15 Humphrey WT, Schepens CL, Elzeneiny IL, et al. The release of subretinal fluid and its complications. In: Pruett RC, Regan CDJ, eds. Retina congress. New York: Appleton-Century-Crofts, 1972:383-90.

16 Mets MB, Wendell ME, Gieser RG. Ocular deviation after retinal detachment surgery. Am J Ophthalmol 1985:99:667-72.

17 Theodossiadis G, Nikolakis S, Apostolopoulos M. Immediate postoperative muscular disturbance in retinal detachment surgery. Mod Probl Ophthalmol 1979:20:367-72.

18 McAllister IL, Meyers SM, Zegarra H, et al. Comparison of pneumatic retinopexy with alternative surgical techniques. Ophthalmology 1988;95:877-83.

19 Ho PC, Tolentino FI. Pseudophakic retinal detachment: surgical success rate with various types of $1 O L$ s. Ophthalmology 1984;91:847-52.

20 Cousins S, Boniuk I, Okun E, et al. Pseudophakic retinal detachments in the presence of various $1 O L$ types. Ophthalmology 1986;93: 1 198-208.

21 Greven CM, Sanders RL, Brown GC, et al. Pseudophakic retinal detachments: anatomic and visual results. Ophthalmology 1992;99:257-62.

22 McAllister IL, Zegarra H, Meyers SM, et al. Treatment of retinal detachments with multiple breaks by pneumatic retinopexy. Arch Ophthalmol 1987; 105:913-16.

23 Irvine AR, Lahey JM. Pneumatic retinopexy for giant retinal tears. Ophthalmology 1994;101:524-8.

24 Melgen SE, Michels M. Pneumatic retinopexy for the treatment of giant retinal dialyses. Am J Ophthalmol 1994; 118:762-5.

25 Tornambe PE, Hilton GF, Kelly NF, et al. Expanded indications for pneumatic retinopexy. Ophthalmology 1988:95:597-600.

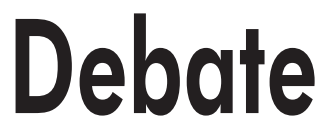

Debate 


\section{Debate Overview}

\section{Debate \\ T Barrie}

T Barrie

Lead clinician

Tennent Institute of

Ophthalmology, Gartnavel

General Hospital

1053 Great Western

Road, Glasgow G12 OYN,

UK
$\mathrm{U}$

until about 20 years ago, the majority of retinal detachments were operated on by general ophthalmologists and the only technique available was scleral buckling combined where appropriate with subretinal fluid drainage and air tamponade. Now specialist vitreoretinal surgeons perform most of the surgery and have a much greater variety of surgical techniques to choose from. The three views presented here define the available options and their indications as seen by proponents of each technique. The results of scleral buckling without drainage of $91 \%$ after one operation and $97 \%$ after one further procedure are very impressive and the key to their success is the time consuming and painstaking preoperative examination. I suspect that there are few other groups who would not be tempted to embark on more complicated surgery where breaks had not been identified preoperatively or in cases of primary failure.

Theoretically, there are many reasons as described by Heinmann why primary vitrectomy should improve the success rate and it is disappointing that the results appear to be poorer with a cumulative reattachment rate of $85 \%$, which is lower than that for scleral buckling without subretinal fluid drainage. This, together with the added complications of vitreous surgery such as accelerated lens opacities and entry site tears, not to mention the extra costs, would seem to weaken the case for primary vitrectomy. It is important however not to overlook the high final success rates in more complex cases.

The concept of being able to reattach the retina by a minor office based procedure is appealing for all the obvious reasons, so why is it still not widely practised around the world? The cumulative success rate of $75 \%$ is obviously lower than with scleral buckling and the relatively high rate of secondary break formation is a further deterrent. There are also other regional factors such as familiarity with the technique and financial pressures that may influence surgical judgment.
Why then are so many cases of retinal detachment undergoing primary vitrectomy? Part of the reason must be the increased familiarity with the techniques gained from diabetic eye disease and trauma, as well as vitreous surgery for advanced PVR and giant retinal tears. Few vitreoretinal surgeons could not be impressed by the ease of examining the peripheral retina intraoperatively afforded by using modern wide field viewing systems, especially when the view is impaired by pseudophakia or media opacities. This has undoubtedly led to less emphasis on the importance of finding breaks preoperatively and hence a lower threshold for recourse to vitreous surgery. Indeed, there is concern that this trend will have a detrimental effect on the examination skills of the next generation of retinal surgeons, who may have a lower rate of finding retinal breaks preoperatively, and therefore a lower threshold for vitreous surgery.

So what conclusions can be drawn? I suspect most surgeons will continue to perform scleral buckling in one form or another. We should perhaps try to reduce the rate of subretinal fluid drainage as, despite refinements, it appears to adversely affect the results. The multicentre trials of scleral buckling will further refine the role of each technique but it would seem unlikely that primary vitrectomy will be readily adopted for simple detachments where the view is good. Pneumatic retinopexy may become more popular in situations where access to an operating theatre is at a premium, but it is likely that its poorer surgical results and increased complication rate will stop its widespread adoption as a primary treatment for retinal detachment.

It is salutary to note that although 70 years have elapsed since Gonin identified that retinal tears were the cause of retinal detachments, the main reason for failure remains the inability to find and subsequently close the break. At this time, although scleral buckling is probably still the most widely used primary procedure, there is no clearly superior surgical technique. 